Título do Trabalho

\title{
A IMPORTÂNCIA DA AVENIDA CONDE DA BOA VISTA NA PAISAGEM DA CIDADE DO RECIFE - PE
}

Nome do Autor (a) Principal

Carlos Eduardo Santos de Lima ${ }^{1}$

Nome (s) do Co-autor (a) (s)

\section{Samuel Othon de Souza da Costa ${ }^{2}$}

Nome (s) do Orientador (a) (s)

Daniel Dantas Moreira Gomes; Maria Betânia Moreira Amador

Instituição ou Empresa

Universidade de Pernambuco - UPE - Campus Garanhuns

E-mail de contato

carloslima.geo@gmail.com; samuk_othon20@hotmail.com

Palavras-chave

Paisagem. Percepção. Vegetação

\section{INTRODUÇÃO}

O presente trabalho faz uma reflexão sobre as transformações ocorridas na Avenida Conde da Boa Vista situada no município do Recife - Pernambuco, decorrentes da ação transformadora dos agentes antrópicos nesse espaço, a partir da percepção dos elementos que desapareceram e / ou se transformaram ao longo do tempo na paisagem geográfica. A referida avenida tem início na Ponte Duarte Coelho etérmino próximo à Praça do Derby, com cerca de dois quilômetros de extensão. A mesma pode ser apreciada na figura 1.

\footnotetext{
${ }^{1}$ Bolsista de Extensão da UPE / Garanhuns

${ }^{2}$ Monitor do Laboratório de Geografia da UPE / Garanhuns
} 


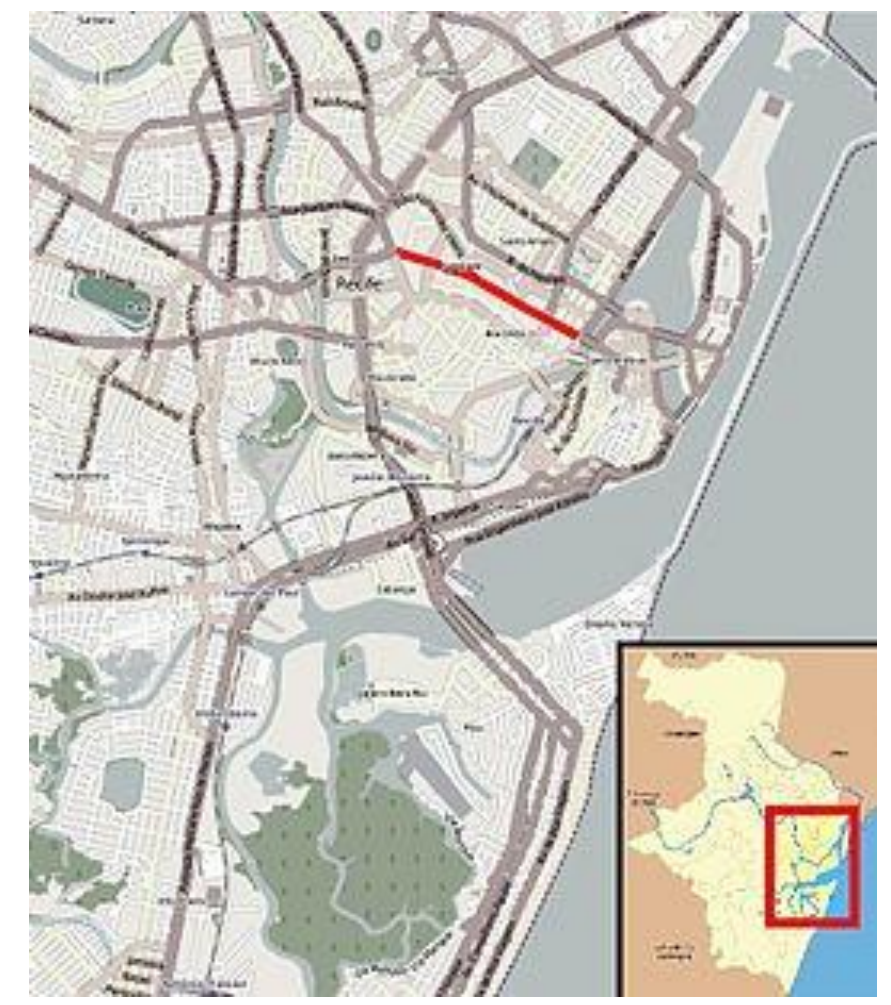

Figura 1

Localização da Avenida Conde da Boa Vista

Fonte:<http://pt.wikipedia.org/wiki/Avenida_Conde_da_Boa_Vista>.

A Avenida Conde da Boa Vista, inicialmente era uma área em que se encontrava uma grande extensãode manguezal, o qual com o tempofoi aterrado para dar lugarao desenvolvimento urbano e às atividades humanas. Esse contexto foi se aprimorando no sentido de viabilizar o sempre crescente fluxo de pessoas, veículos entre outrosna cidade tomando-se como referência o período entre os anos de 1756 a 2012, ou seja dois séculos e meio, aproximadamente.

Para isso, foi retirado todo vestígio de formação vegetal do mangue (Figura 2), que se caracteriza em sua fisionomiacom plantas e arbustos que possuem raízes externas ou aéreas, além de se constituir num ecossistema tido como berçário de muitas espécies aquáticas.Também é importante salientar que a cidade demandou cada vez mais dessa formação e, com isso, mudou radicalmente a fisionomia da paisagem urbana. 




Figura 2

Vestígio de vegetação de mangue em Pernambuco.

Fonte: <http://expoidea.com.br/2012/blog/visoes-da-manguetown-manguezais-urbanos-emdebate/>. Acesso em: 26 set. 2013.

A paisagem é uma das importantes categorias de analise da Geografia e, para tanto, BERTRAND a define como sendo"uma determinadaporção do espaço, o resultado da combinação dinâmica, portanto instável, de elementos físicos,biológicos e antrópicos que, reagindo dialeticamente uns sobre os outros, fazem da paisagem um conjunto único e indissociável, em perpétua evolução" (BERTRAND, 2004, p.141).

A substituição da natureza pela cidade configura-se numa prática normal para aqueles que pretendem de alguma forma se beneficiar dos recursos e da localização geográfica de algumas áreas. Assim, a especulação imobiliária nas regiões litorâneas tem afetado, significativamente, os mangues como é caso de Recife - PE (Figura 3).

Este ecossistema manguezal é de significativo valor ecológico, mas, mesmo assim tem diminuído de extensão ano a ano afetando, nas últimas décadas e, principalmente, na cidade do Recife/PE. Do ponto de vista social afeta diretamente grupos de pessoas que sobrevivem da cata de caranguejos para comercialização, ainda, nos poucos redutos de mangue existentes no perímetro urbano. 
Logo, no último século percebeu-se que com as exíguas faixas restantes de natureza, entre elas os mangues, foram aceleradamente metamorfoseadas pela ação do homem e, na atualidade é visível a proliferação do comércio do centro da cidade (Figura 4), além de bancos; instituições de ensino; templos religiosos; Shopping Center; bares; restaurantes, além de outros equipamentos urbanos.

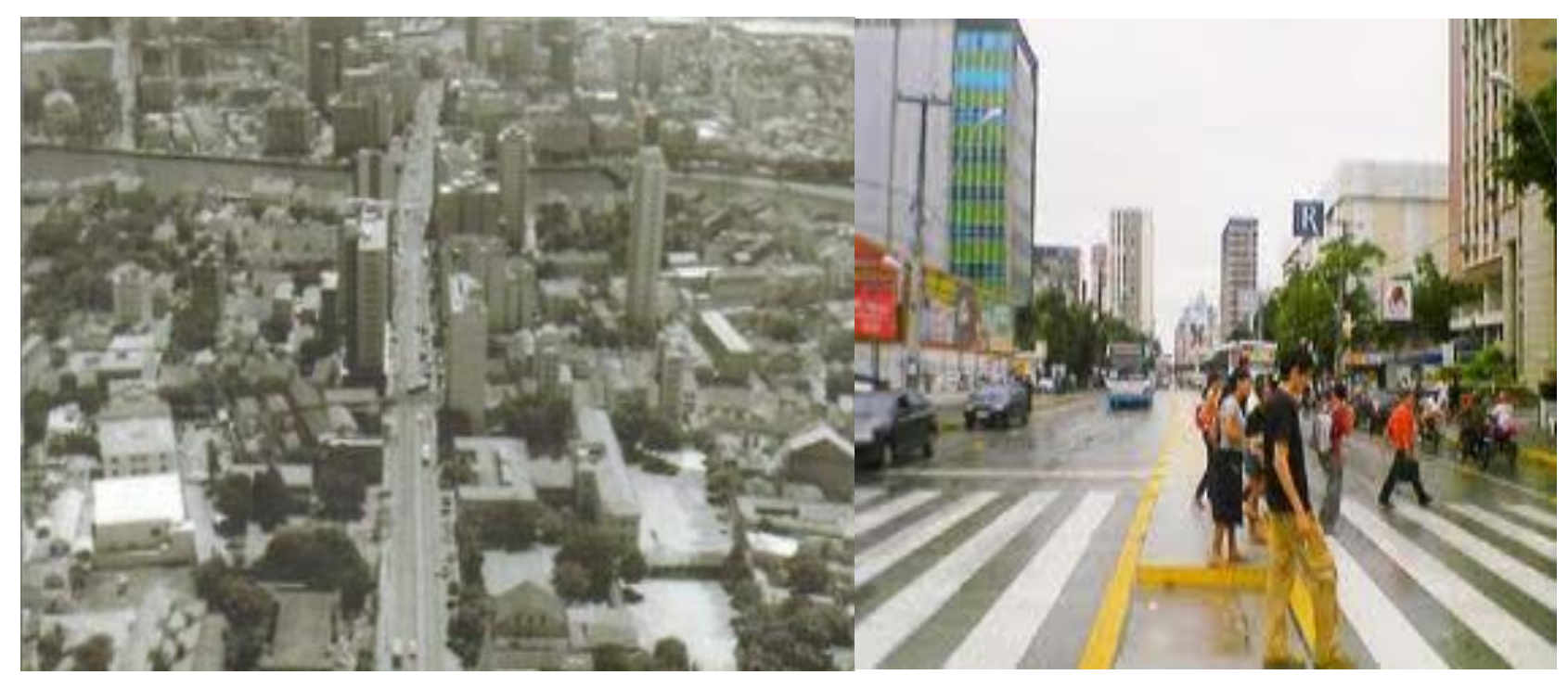

Figura 3 e 4

Avenida Conde da Boa Vista no ano de 1950 / Comercialização de produtos na Avenida

Fonte: <http://www.fotolog.com/recife_prasempre/28759831/>/

Fonte:<http://historiandos.blogspot.com.br/2008_03_01_archive.html>

Essa avenida (Figura 5) encontra-se, nos dias atuais, semelhante a uma floresta de concreto e aço, visto que cerca de 400 mil pessoas e 10 mil veículos transitam pelo local diariamente sendo que, apenas o veículo ônibus circula, aproximadamente, 400 deles por hora (Wikipédia). 


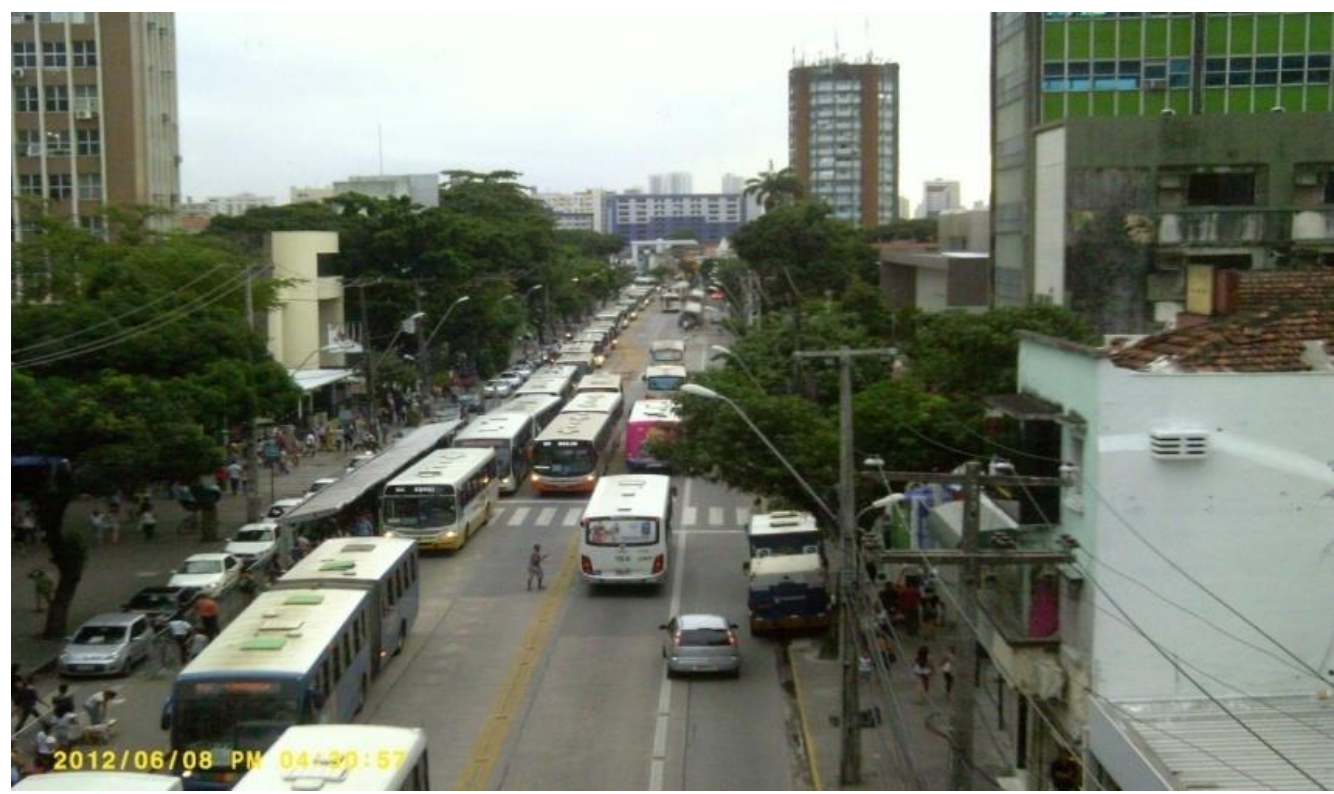

Figura 5

Vista parcial da Conde da Boa Vista, 2012.

Fonte: Lima, 2012.

\section{OBJETIVO GERAL}

Compreender a paisagem geográfica com seus elementos bióticos e abióticos a partir da percepção destes objetos, considerando o tempo e as ações implementadas pelo homem em sua busca por melhores condições de vida.

\section{OBJETIVOS ESPECIFICOS}

Identificar os processos que levaram a uma metamorfose na avenida Conde da Boa Vista, levando em consideração os aspectos socioeconômicos, que podem ser observados em escala tempo/espacial. Assim, caracterizando o desenvolvimento do espaço geográfico de acordo com a necessidade da população.

\section{METODOLOGIA}

Para constituição deste estudo se fez necessário, principalmente, a observação e análise da paisagem, considerando a lógica sistêmica dos processos de interdependência dos elementos, além da utilização de imagens com temporalidade diferente.

\section{RESULTADOS}




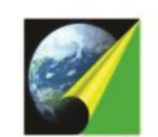

ANAP

A avenida Conde da Boa Vista se desenvolveu a partir da necessidade de espaço para o crescimento da cidade do Recife, a qual se expandiu onde antes era uma área de manguezal e que na sua história recebeu algumas reformas de infraestrutura. E hoje, tem uma paisagem totalmente artificial devido ao desenvolvimento de uma dinâmica populacional bastante intensa.

\section{CONSIDERAÇÕES FINAIS}

Com a crescente ocupação do espaço pelo homem, a paisagem muda radicalmente e com efeitos perturbadores para o meio natural. Assim, traz uma grande exploração de recursos naturais ou a sua substituiçãoem funçãodo desenvolvimento da área urbana.

$\mathrm{Na}$ contemporaneidade, a avenida Conde da Boa Vista é um marco de desenvolvimento na cidade do Recife, pois ela tem uma posição central e influente no comércio, é importante artéria para interligação das diversas vias de acesso aos diferentes bairros da cidade. Portanto, pode-se dizer que ela é realmente "uma selva de pedra", mas de suma importância para a dinâmica urbana de Recife.

\section{REFERENCIAS}

AMADOR, Maria Betânia Moreira. Sistemismo e sustentabilidade: questão interdisciplinar. São Paulo: Scortecci, 2011.

BERTRAND, Georges. Paisagem e geografia física global: esboço metodológico.Curitiba: Editora UFPR. n. 8, p. 141-152, 2004.

História da Avenida Conde da Boa Vista. Disponível em: <http://www2.uol.com.br/JC/sites/boavista/materia01.html>. Acesso em 30 maio de 2012.

Narrativa da Avenida Conde da Boa Vista. Disponível em: $<$ http://basilio.fundaj.gov.br/pesquisaescolar/index.php?option=com_content\&view=article \&id=344\&ltemid $=180>$ 